\title{
UTILIZAÇÃO DAS FERRAMENTAS DE GESTÃO POR GERENTES DE UNIDADES DE ALIMENTAÇÃO E NUTRIÇÃO DO MUNICÍPIO DE SÃO PAULO ${ }^{1}$
}

\author{
THE USE OF MANAGEMENT TOOLS BY \\ FOOD SERVICE MANAGERS OF SAO PAULO CITY
}

\section{Elizabeth Maria Coppola Campos ${ }^{2}$ e Mônica Glória Neumann Spinelli ${ }^{3}$}

\section{RESUMO}

Para atender com permanente qualidade à demanda dos comensais pelas refeições fora do lar, uma boa administração da Unidade de Alimentação e Nutrição (UAN) em cada etapa de produção é fundamental. Para isso, há um conjunto de ferramentas que visam garantir a segurança do alimento e a excelência organizacional. Sendo assim, o objetivo deste trabalho foi identificar a frequência de utilização de ferramentas de gestão em UANs do município de São Paulo, bem como avaliar sua aplicação e verificar quais são as dificuldades de gestão mais comuns. Gestores de 33 UANs, comerciais e institucionais, responderam a um questionário adaptado, contendo um checklist com algumas ferramentas relacionadas à produção e produtividade e questões sobre gestão de pessoas, dentre outras. Constatou-se que $75,75 \%$ tinha alto nível de adesão a tais ferramentas, sendo que a menos utilizada foi a quantificação de sobras e restos $(60,60 \%)$. As maiores dificuldades envolvendo funcionários citadas pelos gestores foram falta de comprometimento e absenteísmo. Dentre suas maiores preocupações, estão a qualidade do atendimento, a crise econômica e os recursos humanos. Concluiu-se que o uso abrangente de ferramentas de gestão otimiza o trabalho, e apesar do alto nível de adesão, ferramentas que auxiliem a redução de desperdícios requerem mais valor, principalmente no intuito de diminuir os custos e aumentar a produtividade.

Palavras-chave: Restaurante. Controle de Qualidade. Produção de alimentos. Recursos Humanos.

\section{ABSTRACT}

In order to serve the demand of the clients for the meals outside home with constant quality, a good administration of a Food Service (FS) in each stage of production is fundamental. For this, there is a set of tools that aim to guarantee food safety and organizational excellence. Therefore, the objective of this work was to identify the frequency of use of management tools in FS of the city of Sao Paulo, as well as to evaluate their application and to verify the most common management difficulties. Managers from 33 FS, both commercial and institutional, responded to an adapted questionnaire, containing a checklist with some tools related to production and productivity and questions about people management, among others. It was found that 75,75\% had a high level of adherence to such tools, and the least used was the quantification of leftovers and remains (60,60\%). The greatest difficulties involving employees cited by managers were lack of commitment and absenteeism. Among their major concerns was the quality of the service, the economic crisis and human resources. It was concluded that the embracing use of management tools optimize the work, and

1 Trabalho de Iniciação Científica - PIBIC.

2 Graduanda em Nutrição, Centro de Ciências Biológicas e da Saúde, Universidade Presbiteriana Mackenzie, São Paulo - SP, Brasil. E-mail: beth_coppola@hotmail.com

3 Professora adjunta do curso de Nutrição, Centro de Ciências Biológicas e da Saúde, Universidade Presbiteriana Mackenzie, São Paulo - SP, Brasil. E-mail: monica.spinelli@mackenzie.br 
despite the high level of adherence, tools that help reduce waste require more value, mainly in order to reduce costs and increase productivity.

Keywords: Restaurant. Control of Quality. Food Production. Workforce

\section{INTRODUÇÃO}

Tendo em vista o grande impacto que as Unidades de Alimentação e Nutrição (UANs) possuem, tanto no cotidiano de seus comensais quanto na economia, questiona-se a adequação da administração desses estabelecimentos, considerando seu complexo funcionamento que engloba várias etapas. Cada um desses processos deve ser padronizado e cuidadosamente realizado, para que a finalidade seja não somente o lucro, mas acima de tudo o fornecimento de refeições de qualidade à população, garantindo sua satisfação com o serviço (ABREU; SPINELLI; SOUZA PINTO, 2016)

O planejamento é primordial em se tratando de qualquer atividade, e nas UANs não é diferente. É a partir dele que se definem todos os aspectos relacionados ao trabalho, desde as dimensões ambientais do estabelecimento, os fornecedores, o tipo de público atendido, as refeições servidas, dentre outros, até o orçamento para que o trabalho se concretize. A falta de planejamento pode implicar no fracasso da empresa. Porém, ainda que haja planejamento e não seja feito um acompanhamento constante para verificar sua aplicação na prática, o funcionamento da UAN pode acabar se distanciando do que foi planejado (ABREU; SPINELLI; SOUZA PINTO, 2016; CHIAVENATO, 2020).

Sendo assim, é de expressiva importância o cumprimento dos pilares da administração, visando combater imprevistos e atingir as expectativas dos clientes, consequentemente obtendo retorno (CHIAVENATO, 2020).

A globalização é um fator que aumentou a necessidade de aperfeiçoamento contínuo dos produtos e serviços para satisfazer as exigências dos clientes, requisitando da UAN todo um processo administrativo bem executado, composto pelos quatro pilares da administração: planejamento, organização, direção e controle (ABREU; SPINELLI; SOUZA PINTO, 2016; CHIAVENATO, 1994).

Compete ao nutricionista da UAN planejar, organizar, dirigir, supervisionar e avaliar os serviços de alimentação e nutrição, para cumprir todas as atividades obrigatórias e complementares designadas, de acordo com a Resolução 600/2018 do Conselho Federal de Nutricionistas (BRASIL, 2018).

No entanto, muitas UANs são empresas familiares, dirigidas por empresários com pouca qualificação na área. Ao se depararem com os principais problemas cotidianos, não conseguem tomar as decisões corretas. Frequentemente há falta de sistema de custeio e programa para controle e garantia da qualidade (MONTENEGRO, 2003; REBELATO, 1997).

Estudos indicam que o setor de produção de refeições possui baixa qualificação profissional, em relação às ocupações operacionais. Há dificuldades na contratação dos funcionários em várias ocupações por falta de experiência, de capacitação profissional e de responsabilidade refletindo, as- 
sim, a realidade do setor em relação à profissionalização (CAVALLI; SALAY, 2007; ENZ, 2004; PROENÇA, 1999).

A partir da avaliação de processos, é possível assegurar também a segurança do alimento (ABREU; SPINELLI; SOUZA PINTO, 2016). Segundo Cavalli e Salay (2007), para ter um bom controle de qualidade e segurança do alimento dentro do ambiente de trabalho são necessárias a educação e formação voltada aos operadores que trabalham em serviços de alimentação, com o objetivo de prevenir doenças que possam vir dos próprios alimentos.

Milhões de pessoas são afetadas por doenças de origem alimentar, e por este motivo a preocupação com a qualidade dos alimentos está sendo cada vez maior (WHO, 2000). Para transformar essa situação, de acordo com Akutsu et al. (2005 b) estão sendo aplicadas ferramentas como as Boas Práticas de Fabricação (BPF), Procedimentos Operacionais Padrão (POPs) e a Análise de Perigos e Pontos Críticos de Controle (APPCC).

Nesse contexto, o objetivo deste trabalho foi identificar quais ferramentas de gestão são utilizadas em UANs do município de São Paulo, bem como avaliar a frequência de aplicação dessas ferramentas e verificar quais são as dificuldades de gestão mais comuns.

\section{MATERIAL E MÉTODOS}

Trata-se de um estudo observacional descritivo de delineamento transversal, realizado a partir de coleta de dados primários. O questionário aplicado foi aplicado presencialmente ou enviado por email após contato inicial e foi composto por quatro seções: Dados do Estabelecimento, Dados do Gestor Entrevistado, Avaliação de Produção e Produtividade e Gestão de Pessoas. As duas primeiras seções caracterizavam a UAN e o entrevistado com informações básicas. A seção Avaliação de Produção e Produtividade se referia a um checklist contendo vários tipos de ferramentas de gestão, cujas respostas possíveis eram "sim", se utilizada ou "não", se não utilizada. Foi aferido N.O (não observado) nos casos em que a questão não foi respondida. A última seção, Gestão de Pessoas, foi composta por questões relacionadas aos funcionários, além de perguntas abertas sobre as principais dificuldades do gestor no que concerne aos funcionários e à UAN.

O porte das UANs foi classificado de acordo com a definição de Sant'Ana (2012): pequeno porte: até 500 refeições por dia; médio porte: 501 a 2000 refeições por dia; grande porte: 2001 a 10000 refeições por dia.

Os dados foram tabulados no programa Microsoft Excel. Aqueles provenientes da seção Avaliação de Produção e Produtividade foram analisados de acordo com um sistema de avaliação arbitrariamente estabelecido para este estudo, considerando o percentual de adesão, uma vez que não foram encontradas referências. Assim sendo, de 0 a 7 ferramentas de gestão utilizadas $(\leq 41 \%)$ o nível de adesão foi classificado como baixo; de 8 a 11 (47\%-64\%) foi considerada média adesão 
e de 12 a 17 (70\%-100\%), alta adesão. Os demais dados foram analisados a partir de comparações com achados da literatura.

Os dados foram coletados entre agosto de 2017 e abril de 2018. Foi adotada amostragem por conveniência, sendo convidados a participar gestores de UANs localizadas no município de São Paulo.

Como instrumento de coleta, no momento da entrevista foi aplicado ao gestor da UAN disponível um questionário com perguntas abertas e fechadas, adaptado de Abreu, Spinelli e Souza Pinto (2016), Cavalli e Salay (2007) e Enz (2004). Visando atingir um número maior de participantes, além da entrevista presencial, utilizou-se também um questionário online, disponibilizado em uma plataforma de criação de formulários. Tal questionário foi enviado por e-mail para alguns participantes após contato inicial, com objetivo de se tornar mais acessível, uma vez que a participação durante o expediente era inviável.

Foram devidamente explicados aos proprietários dos estabelecimentos e aos entrevistados o objetivo e procedimentos do estudo, que riscos como algum tipo de desconforto permitiria ao participante desistir da pesquisa a qualquer momento e o caráter sigiloso do estudo. Esta pesquisa recebeu aprovação ética CAAE 48483015.7.0000.0084.

\section{RESULTADOS E DISCUSSÃO}

A amostra foi composta por 33 UANs, sendo 23 comerciais e 10 institucionais. A maioria era de pequeno porte (51,5\%); as de médio porte eram $42,4 \%$ e apenas $6,06 \%$ eram de grande porte. $\mathrm{O}$ almoço era a principal refeição servida (97,0\%). Ainda, 57,6\% $(\mathrm{n}=17)$ dos restaurantes possuíam serviço do tipo à la carte; $39,4 \%(n=13)$ do tipo self-service e $9,1 \%(n=3)$ eram cantinas escolares.

Pouco mais da metade dos participantes eram mulheres (57,6\%), cuja média de idade era de 42 anos. Quanto ao grau de escolaridade, $12,1 \%$ concluíram até o $1^{\circ}$ grau; $21,2 \%$ cursaram o $2^{\circ}$ grau e $63,6 \%$ completaram o $3^{\circ}$ grau. Desses, ao menos $27,3 \%$ tinham alguma formação relacionada à Nutrição. Outros 6,1\% eram pós-graduados em Administração e afins. Os demais não revelaram a formação. Em relação à jornada de trabalho, a maioria $(36,4 \%)$ apresentou 8 horas diárias, sendo que o mínimo referido foi de 6, e o máximo, 17 horas. A média de tempo de serviço na empresa foi de 8,53 anos, com desvio padrão de $\pm 8,23$.

Constatou-se que mais da metade das UANs (66,7\%) possuía nutricionista como responsável técnico (RT). Pereira, Vieira e Fonseca (2016) obtiveram dados de 20,0\% de presença de responsáveis técnicos em estabelecimentos, independentemente de sua formação. No estudo de Campos, Sá e Lissoni (2016), foi encontrado 38\% de nutricionistas nessa função. Segundo os autores, o RT tem sua importância por atuar de maneira decisiva na área de segurança alimentar, com implantação de BPF e POPs que, além de atenderem à legislação, auxiliam no treinamento, informação e capacitação de toda a equipe. O nutricionista é um profissional habilitado para tal, pois detém os conhecimentos em 
relação à segurança alimentar e exigências higienicossanitárias, e responde integralmente de forma ética, civil e penal pelo estabelecimento (BRASIL, 2018).

Conforme mostra o Gráfico 1, os gestores, em sua maioria $(75,7 \%)$, relataram uma alta adesão às ferramentas de gestão, ou seja, utilizam acima de $70 \%$ das ferramentas citadas neste estudo.

Gráfico 1 - Nível de adesão às ferramentas de gestão por gestores de UANs. São Paulo, 2018.

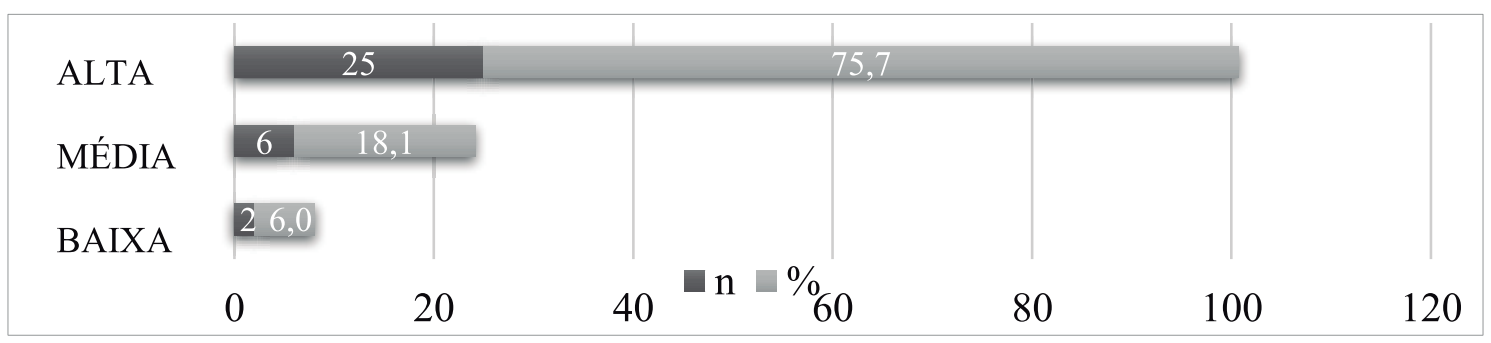

Fonte: Dados da pesquisa

Na Tabela 1 estão contidos os dados referentes à utilização de cada uma das ferramentas de gestão verificadas neste estudo. Destaca-se que planejamento de cardápio, avaliação das condições de trabalho e avaliação de saúde dos empregados foram unanimidade de utilização entre os gestores.

Tabela 1 - Utilização de ferramentas de gestão em UANs referidas pelos gestores. São Paulo, 2018.

\begin{tabular}{|lcccccc|}
\hline \multicolumn{1}{c}{ Ferramenta de gestão } & SIM & \% & NÃO & $\%$ & N.O & $\%$ \\
\hline Planejamento de cardápio & 33 & 100 & 0 & 0 & 0 & 0 \\
\hline Receituário padrão & 27 & 81,8 & 10 & 30,3 & 0 & 0 \\
\hline Controle de estoque & 30 & 90,9 & 3 & 9,0 & 0 & 0 \\
\hline Controle de custos & 31 & 93,9 & 2 & 6,0 & 0 & 0 \\
\hline Planejamento das requisições de alimentos e materiais & 30 & 90,9 & 3 & 9,0 & 0 & 0 \\
\hline Cadastro de fornecedores & 32 & 96,9 & 1 & 3,0 & 0 & 0 \\
\hline Vistoria técnica & 30 & 90,9 & 3 & 9,0 & 0 & 0 \\
\hline Controle da ergonomia e salubridade dos empregados & 29 & 87,8 & 4 & 12,1 & 0 & 0 \\
\hline Avaliação das condições de trabalho & 33 & 100 & 0 & 0 & 0 & 0 \\
\hline Avaliação de saúde dos empregados & 33 & 100 & 0 & 0 & 0 & 0 \\
\hline Existência de EPIs & 28 & 84,8 & 3 & 9,0 & 2 & 6,0 \\
\hline APPCC & 30 & 90,9 & 2 & 6,0 & 1 & 3,0 \\
\hline Quantificação de restos e sobras & 20 & 60,6 & 12 & 36,3 & 1 & 3,0 \\
\hline Contemplar dimensão ambiental no planejamento das refeições & 26 & 78,7 & 5 & 15,1 & 2 & 6,0 \\
\hline Avaliações de produção e produtividade & 27 & 81,8 & 5 & 15,1 & 1 & 3,0 \\
\hline Sistemas de fluxos & 25 & 75,7 & 7 & 21,2 & 1 & 3,0 \\
\hline Indicadores de produtividade & 22 & 66,6 & 10 & 30,3 & 1 & 3,0 \\
\hline
\end{tabular}

Fonte: Dados da pesquisa

De acordo com Noveletto e Proença (2004), o cardápio é a base do processo produtivo, que vai guiar todas as suas etapas. Este pode tanto determinar quanto se adequar aos equipamentos, pessoal e tempo disponíveis, como também facilitar o planejamento de compras e orçamento, conforme Akutsu (2005 a). Trata-se de uma ferramenta fundamental para o funcionamento de qualquer UAN. 
Outra ferramenta muito útil para a organização de vários setores da UAN é o receituário padrão, utilizado por 81,8\% dos gestores. Souza e Marsi (2015), Japur et al. (2012), Lins e Maciel (2007) concordam que este possibilita o registro e padronização das quantidades de matéria-prima, dos processos de produção e da montagem e apresentação dos pratos. Além disso, auxilia no controle de custos, pois facilita as projeções de compras e especificações de mercadorias. Também garante preparações com a composição nutricional sempre parecida, contribuindo para a promoção da saúde dos comensais. Segundo Akutsu et. al (2005 a), a padronização facilita o treinamento, elimina dúvidas, gera maior segurança e, consequentemente, diminui perdas em qualidade e produtividade, já que parte desses problemas se deve aos funcionários que, por serem de turnos diferentes, executam as tarefas de formas diferentes.

Apesar de 100\% dos gestores afirmarem que há avaliação das condições de trabalho e de saúde dos funcionários, itens como o controle da ergonomia e salubridade dos empregados e existência de EPIs não obtiveram a mesma unanimidade (87,9\% e 84,8\%, respectivamente), mesmo estando interligados.

A disponibilidade de EPIs nem sempre se encontra relacionada ao seu uso, como indica o estudo de Lima et al. (2017) que encontraram adesão inferior a 60,0 \%.

Segundo Abreu, Spinelli e Souza Pinto (2019) e Colares e Freitas (2007), os locais destinados ao preparo das refeições apresentam, em geral, ruído excessivo, temperatura elevada, iluminação deficiente, arranjo físico e instalações precários. Estas condições impactam diretamente na produtividade e na saúde dos colaboradores. A avaliação das condições de trabalho tem como objetivo garantir o controle da ergonomia e salubridade dos funcionários. Este controle, por sua vez, deve minimizar esse conjunto de fatores, a partir de medidas de prevenção dos riscos ergonômicos, pois zelar pelos funcionários significa menor ocorrência de acidentes, doenças e, consequentemente, menores índices de absenteísmo, conforme Albuquerque (2012). Além disso, a legislação preconiza que, para evitar a veiculação de DTAs, a saúde do manipulador de alimentos deve ser comprovada por meio de atestados médicos, exames e laudos laboratoriais originais ou suas cópias (BRASIL, 2013). Tais exames devem ser requeridos na admissão, na demissão e periodicamente (VAZ, 2002).

Os EPIs, segundo Fonseca (2009) protegem a integridade física do trabalhador, pois previnem acidentes e contaminação. Também podem contribuir para agilizar processos e possibilitar aumento de produtividade e da satisfação no ambiente de trabalho.

Apesar da adesão não ter sido plena, o uso de algumas ferramentas foi bastante frequente, igual ou acima de 80,0\%, como vistoria técnica, controle de estoque, planejamento de requisições de alimentos e materiais, cadastro de fornecedores e controle de custos.

Ainda, dentre as atribuições do RT, uma das funções primordiais desse profissional é a vistoria técnica (BRASIL, 2018), ferramenta adotada por 90,9\%. Porém, é preocupante que, dos dois estabelecimentos que não a fazem, um deles possua nutricionista como RT. De acordo com Fonseca e Santana (2012), o nutricionista, enquanto vigilante da saúde na UAN, não deve se permitir atuar apenas como cuidador do processo produtivo, pois ao assim fazer, negligencia o perfil profissional 
que o caracteriza, deixando de ser um promotor de saúde para, então, ser mais um cumpridor de metas financeiras.

O RT pode também implementar o método APPCC, que se trata não apenas de uma ferramenta, mas de uma exigência da legislação a todos os estabelecimentos que processam e prestam serviços de alimentação ou vigilância sanitária (BRASIL, 1993). As BPF e os POPs são duas ferramentas essenciais aos estabelecimentos que precedem o APPCC. Segundo Akutsu et al. (2005 b), através do APPCC, faZ-se um controle de cada etapa de processamento e enfatiza um maior cuidado com os pontos críticos, ou seja, de maior perigo de contaminação, colaborando para a segurança e garantia de qualidade do alimento. De acordo com Melo (2007), o sistema pode trazer vantagens inclusive econômicas, como redução de perdas de matérias-primas, de devolução de produtos e de contaminações, conquistas de novos mercados, atendimento a requisitos de clientes e pré-requisitos para sistemas de certificação.

Dos $90,9 \%$ que realizavam controle de estoque, 53,3\% o faziam manualmente, $43,3 \%$ utilizavam sistemas informatizados e ainda, 3,4\% realizava das duas formas. Desses 53,3\%, 56,3\% eram estabelecimentos de médio porte, $37,5 \%$ de pequeno porte e $6,2 \%$ de grande porte. Para o Sebrae (2012), a informatização pode auxiliar de forma significativa o controle do estoque, resultando em uma melhor gestão dos recursos financeiros. Quanto maior o número de itens que se possui em estoque, mais um sistema informatizado irá facilitar o controle, que é fundamental a fim de evitar possíveis furtos e assegurar a identificação precoce de incorreções no lançamento. Kilpp (2015) afirma que um sistema informatizado permite controlar os dias existentes de estoque, o custo diário da unidade, a quantidade de cada item, dentre outros fatores. A ausência desse controle pode levar à perda de insumos, materiais e recursos.

Quanto ao planejamento de requisições de alimentos e materiais, dos 90,9\% que o faziam, $82,1 \%$ asseguravam seu cumprimento. Sobre a periodicidade das requisições, as de frequência unicamente semanal (36,4\%) e unicamente diária (30,3\%) eram as mais comuns. Em terceiro lugar, vieram aquelas sem frequência fixa, podendo ser diárias, semanais, quinzenais ou mensais, de acordo com as necessidades de estoque (24,2\%). Conforme Abreu, Spinelli e Souza Pinto (2019) e Teixeira et al. (2006), o planejamento de compras é feito a partir do cardápio e do receituário padrão, considerando o per capita bruto dos alimentos e o número estimado de refeições que serão servidos com o objetivo de evitar excesso ou falta de insumos.

O cadastro dos fornecedores (97,0\%) é altamente recomendado por Chiavenato (2014), ao permitir que se elabore um banco de dados sobre as compras efetuadas com cada um deles, pois isso facilita as futuras pesquisas e seleções de fornecedores. Assim, possibilita a compra de produtos confiáveis e de qualidade, o que gera menos gastos e menos desperdício.

Em relação ao controle de custos, apesar de 93,9\% o fazerem, apenas 54,5\% estão atingindo as metas, conforme afirmaram os próprios gestores. De acordo com Fonseca e Santana (2012), nesses casos, a primeira atitude geralmente tomada é a alteração do cardápio, substituindo as preparações mais caras. Isso, porém, pode acarretar na perda de clientela, especialmente em restaurantes comerciais. 
Ressaltam ainda que se deve obedecer a um critério econômico na escolha dos alimentos, observando safra, descontos e embalagens. As autoras também recomendam que realizar o controle de recebimento, manipulação e distribuição de gêneros, planejamento de cardápios, de compras e controle de estoque é imprescindível no sentido de assegurar a qualidade do produto, evitando o desperdício e auxiliando no controle dos custos.

As ferramentas menos adotadas foram as medidas para quantificar restos e sobras, por $60,6 \%$. O estudo de Pereira, Vieira e Fonseca (2016) obteve resultados inferiores, com 33,3\% de adesão. Fonseca e Santana (2012) consideram o desperdício em uma UAN como as sobras e os restos dos alimentos e, ainda, que o fator mais grave causador do desperdício é o planejamento inadequado do número de refeições produzidas. Melo, Macedo e Calazans (2018) afirmam que o desperdício foi identificado como principal gerador de custos em UAN, e recomendam efetuar a monitoração adequada de cortes, aparas, modo de preparo e recebimento de gêneros na cozinha, permitindo melhoria no controle de custos, assim como integração de metas de produção aos objetivos sustentáveis e à estratégia da empresa. Nessa lógica, Gomes e Jorge (2012), concordam que o controle diário de perdas serve como subsídio para implantar medidas de racionalização, redução de desperdícios e otimização da produtividade.

Visando aumentar a produtividade, uma das ferramentas com este objetivo é contemplar a dimensão ambiental no planejamento das refeições, adotada por $78,8 \%$ dos gestores. Conforme Noveletto e Proença (2004), faz-se necessário observar as condições dos equipamentos e áreas disponíveis para o preparo de refeições. Deve-se, também, observar o modo de preparo, verificando os tipos de equipamentos que serão utilizados no cardápio, visando evitar que várias preparações necessitem utilizar o mesmo equipamento ao mesmo tempo. Estas atitudes não só agilizam o preparo como também ampliam a ergonomia dos colaboradores, exigindo menos movimentos e posições repetitivos.

Os sistemas de fluxos, utilizados por 75,8\%, também podem facilitar o trabalho e contribuir para melhor produtividade. Segundo Sant'Ana (2012), as instalações devem ser projetadas de forma a facilitar os procedimentos operacionais por meio de fluxos contínuos, sem o cruzamento de etapas e linhas do processo de produção, além de satisfazer o comensal com o serviço oferecido.

Os indicadores de produtividade foram a segunda ferramenta menos utilizada. Indicadores como o Índice de Produtividade Individual (IPI), de acordo com Abreu, Spinelli e Souza Pinto (2016), avaliam o rendimento da mão de obra em função do número de refeições produzidas e servidas. São também uma forma de avaliação da ergonomia dos funcionários, como mostra o estudo de Sandoval e Spinelli (2017). Santana (2002) afirma que a ergonomia evidencia a distância entre o trabalho prescrito e o real. Logo, assegurar a ergonomia dos colaboradores significa melhorar a produtividade e reduzir o absenteísmo devido afastamentos por lesões.

Todos os tópicos do checklist devem ser reavaliados pelos gestores periodicamente. Destes, $81,81 \%$ disseram realizar avaliações de produção e produtividade. Estas avaliações fazem parte do processo de controle, que, segundo Chiavenato (2020), deve assegurar que os procedimentos se 
ajustem o máximo possível ao resultado previamente estabelecido determinando ações corretivas, caso necessário.

Em 78,8\% das UANs, os funcionários não possuíam cursos profissionalizantes. Cavalli e Salay (2007) encontraram resultados semelhantes nos self-services por quilo (79,0\%), nas churrascarias $(77,6 \%)$ e nos fast-foods $(78,3 \%)$ avaliados. Ainda de acordo com as autoras, para a segurança do alimento é de extrema relevância a capacitação dos colaboradores. Contudo, os treinamentos para a gestão da qualidade requerem custos e necessitam de profissionais da área de alimentos e nutrição para a sua concretização. As empresas, muitas vezes, não possuem condições econômicas ou até não consideram importante essa capacitação para o setor.

O critério de contratação preferido entre os gerentes foi a experiência $(81,8 \%)$. Já, nas empresas do estudo de Cavalli e Salay (2007), 19,6\% não se valiam de nenhum critério fora a indicação, pois consideravam ser melhor treinar do que admitir pessoal experiente, com vícios. Abreu, Spinelli e Souza Pinto (2016) acreditam que levar em consideração o potencial do candidato é mais importante do que suas experiências anteriores, pois isso não necessariamente significa aptidão. Nessa linha, Fonseca e Santana (2012) destacam que uma característica importante do nutricionista de UAN é saber reconhecer os talentos da sua unidade; cabe ao profissional encaixá-los na atribuição mais adequada. O nível de escolaridade, citado por apenas 18,2\% dos gestores, também é um requisito essencial para o bom andamento do serviço.

Foi declarada a presença de sistema de capacitação dos funcionários entre $66,7 \%$ dos participantes. Dos gestores, 92,3\% afirmaram realizar treinamento inicial, enquanto 84,4\% mantinham treinamentos periódicos, geralmente mensais, semestrais ou anuais. Segundo Proença (1999), a avaliação de desempenho é considerada primordial para verificar problemas, como o absenteísmo no trabalho, pois, muitas vezes, o próprio funcionário não tem clareza dos dias que faltou e também dos problemas que isso causa ao sistema produtivo da empresa. Resultado parecido foi obtido no estudo de Pereira, Vieira e Fonseca (2016), em que 80\% dos restaurantes realizavam treinamentos periódicos. De acordo com Chiavenato (2010), treinamentos são indispensáveis para ensinar os funcionários, principalmente os recém-admitidos, a executar o trabalho de acordo com os métodos e processos admitidos pela empresa. A ausência dessa capacitação leva à falta de eficiência, de produtividade e de qualidade do serviço.

A Tabela 2 descreve os principais problemas enfrentados com funcionários. Verificou-se que 45, 5\% dos gestores mencionaram ao menos um problema, enquanto o máximo de problemas mencionados pelo mesmo gestor foram quatro, apenas por 3,0\%. Falta de comprometimento e absenteísmo foram os mais frequentes, com $33,3 \%$ e $27,3 \%$, respectivamente.

Diversamente, nos achados de Pereira, Vieira e Fonseca (2016), 47,0\% dos funcionários dos estabelecimentos apresentavam média de nenhuma falta ao mês. Segundo os autores, as faltas podem prejudicar a qualidade do serviço, além de exigir um maior esforço por parte dos outros funcionários da equipe e aumento de despesas com treinamentos e cursos para novos funcionários. 
A falta de comprometimento pode ser um reflexo de insatisfação. Sobre isso, Fonseca e Santana (2012) aconselham discutir com os funcionários formas de melhorias no trabalho, bem como ouvi-los. Buscar sempre motivá-los, reconhecendo sua importância, permite que o ambiente de trabalho seja agradável. A avaliação periódica dos funcionários, discutida anteriormente, é uma forma de trazer a eles um retorno de suas potencialidades e fragilidades, para que saibam onde devem se aprimorar e reforcem aquilo que já é positivo.

Tabela 2 - Principais problemas envolvendo funcionários citados por gestores de UANs. São Paulo, 2018.

\begin{tabular}{lcc}
\hline \multicolumn{1}{c}{ Problema citado } & n & \% \\
\hline Nenhum & 6 & 18,1 \\
\hline Absenteísmo & 9 & 27,2 \\
\hline Falta de comprometimento & 11 & 33,3 \\
\hline Atitudes não profissionais & 4 & 12,1 \\
\hline Atrasos & 6 & 18,1 \\
\hline Falta de qualificação & 5 & 15,1 \\
Relacionamento interpessoal & 2 & 6,0 \\
Falta de plano de carreira & 3 & 9,0 \\
\hline \multicolumn{2}{c}{ Fonte: Dados da pesquisa. } \\
\hline
\end{tabular}

A Tabela 3 revela as maiores preocupações dos entrevistados. Verificou-se que $57,6 \%$ dos gestores mencionaram pelo menos uma dificuldade, enquanto o máximo de dificuldades citadas pelo mesmo gestor foi 3, por 3,0\%. Três questões foram igualmente comuns: a qualidade do atendimento, a crise econômica e os recursos humanos, todos com 27,3\%. Com exceção destes, em segundo lugar estão preocupações envolvendo os custos, com 21,2\%. Pode-se afirmar que preocupações com questões financeiras atingem 66,7\% dos gestores, incluindo meta de vendas, crise econômica e custos.

No estudo de Enz (2004), realizado com gestores nos EUA, também foi detectado que a maior preocupação deles estava relacionada aos recursos humanos $(15,0 \%)$. Por outro lado, a gestão de custos preocupava apenas 7,0\%. Segundo Fonseca (2002) as causas do insucesso no setor de alimentação coletiva são motivadas tanto pela falta de planejamento, quanto pela falta de preparo dos gestores da UAN.

Dada a atual situação de instabilidade econômica do país, fato preocupante a muitos gestores, torna-se ainda mais relevante o investimento em diversas ferramentas de gestão, com o intuito de agregar qualidade ao serviço e garantir a satisfação tanto dos clientes quanto dos colaboradores.

Tampouco foi possível notar padrões entre os problemas referidos pelos gestores de cada tipo de UAN. Excepcionalmente, um dos problemas citados em "Outros" foi a falta de alimentos, exclusivo de uma UAN escolar pública, demonstrando a má gestão pública dos recursos. Já, o outro, referente a uma UAN escolar particular, foi a preocupação com a variabilidade do cardápio. 
Tabela 3 - Questões que mais preocupam gestores de UANs. São Paulo, 2018.

\begin{tabular}{llc}
\hline \multicolumn{1}{c}{ Questão citada } & n & \% \\
\hline Qualidade do atendimento & 9 & 27,2 \\
\hline Meta de vendas & 6 & 18,1 \\
Crise econômica & 9 & 27,2 \\
\hline Recursos humanos & 9 & 27,2 \\
Custos & 7 & 21,2 \\
\hline Legislação & 3 & 9,0 \\
Nenhum & 1 & 3,0 \\
\hline Outros & 2 & 6,0 \\
\hline
\end{tabular}

Fonte: Dados da pesquisa

\section{CONCLUSÃO}

Através deste estudo, foi possível evidenciar que as ferramentas de gestão estão interligadas, sendo que a utilização de uma contribui para a otimização de outra. Por isso, quanto mais abrangente for a adesão a elas, maiores serão as chances de sucesso dos estabelecimentos. Os dados sobre a utilização das ferramentas de gestão alegados pelos participantes são bastante satisfatórios. No entanto, considerando as dificuldades apontadas pelos gestores, pode-se inferir que nem sempre elas sejam adequadamente aplicadas.

Há preocupações peculiares a gestores de determinados estabelecimentos, como as UANs escolares, tanto pelo fato de haver uma gestão pública por trás, tanto pelo público alvo específico a qual essa alimentação é destinada. Fora isso, os gestores partilham basicamente das mesmas dificuldades, sendo que as preocupações com finanças estão entre as maiores. Nesse sentido, requer-se maior atenção com medidas que visem redução de desperdício, visto que estão sendo negligenciadas a despeito de sua importância. A forma de se lidar com os recursos humanos também precisa ser revista, prezando mais pela capacitação dos funcionários do que apenas pela experiência.

Algumas ferramentas acabam por deixar de serem adotadas por desconhecimento, ou pela crença de que não são necessárias em estabelecimentos de menor porte. Sendo assim, é importante que os gestores se mantenham atualizados e tenham as devidas competências para implementá-las, a fim de que haja melhora da qualidade, maior satisfação, tanto da clientela quanto dos colaboradores, e até mesmo um controle mais eficaz dos custos.

\section{AGRADECIMENTOS}

Ao programa MackPesquisa e à todas as pessoas envolvidas direta ou indiretamente para que este trabalho fosse possível. 


\section{REFERENCIAS}

ABREU, E. S.; SPINELLI, M. G. N.; SOUZA PINTO, A. M. Gestão de Unidades de Alimentação e Nutrição: um modo de fazer. 6. ed. São Paulo: Editora Metha, 2016. 400 p.

ABREU, E. S.; SPINELLI, M. G. N.; SOUZA PINTO, A. M. Gestão de Unidades de Alimentação e Nutrição: um modo de fazer. 7. ed. São Paulo: Editora Metha, 2019. 416p.

AKUTSU, R. C. et al. A ficha técnica de preparação como instrumento de qualidade na produção de refeições. Revista de Nutrição Campinas, v. 18, n. 2, p. 277-279, 2005. (a)

AKUTSU, R. C. et al. Adequação das boas práticas de fabricação em serviços de alimentação. Revista de Nutrição Campinas, v. 18, n. 3, p. 419-427, 2005. (b)

ALBUQUERQUE, E. N. de et al. Riscos físicos em uma unidade de alimentação e nutrição: implicações na saúde do trabalhador. Revista da Associação Brasileira de Nutrição, v. 4, n. 1, p. 40-47, 2012.

BRASIL. Conselho Federal de Nutricionistas. Resolução n 600/2018. Dispõe sobre a definição das áreas de atuação do nutricionista e suas atribuições, indica parâmetros numéricos mínimos de referência, por área de atuação, para a efetividade dos serviços prestados à sociedade e dá outras providências. Disponível em: https://bit.ly/3tDSYU0. Acesso: 28/05/2018.

BRASIL. Ministério da Saúde. Portaria CVS 5, de 09 de abril de 2013. Aprova o regulamento técnico sobre Boas Práticas para serviços de alimentação, e o roteiro de inspeção. Diário Oficial da União, Brasília, DF, 19 de abril de 2013.

BRASIL. Ministério da Saúde. Portaria 1428, de 26 de novembro de 1993. Regulamento Técnico para Inspeção Sanitária de Alimentos. Diário Oficial da República Federativa, Brasília, DF, 2 dez. 1993.

CAMPOS, L. de L.; SÁ, M. A. R. de; LISSONI, T. C. Caracterização das visitas realizadas pelos agentes da vigilância sanitária do setor alimentício em Uberlândia MG. Higiene alimentar, v. 30, n. 252/253, p. 163-169, 2016.

CAVALLI, S.; SALAY, E. Gestão de pessoas em unidades produtoras de refeições comerciais e a segurança alimentar. Revista de Nutrição, v. 20, n. 6, p. 657-667, 2007. 
CHIAVENATO, I. Administração de empresas: uma abordagem contingencial. 3. ed. São Paulo: Makron Books, 1994. 735 p.

CHIAVENATO, I. Administração nos Novos Tempos - Os Novos Horizontes em Administração. 4. ed. SP: Atlas, 2020.384p.

CHIAVENATO, I. Gestão de materiais: uma abordagem introdutória. 3. ed. Barueri, SP: Manole, 2014. 209 p.

CHIAVENATO, I. Iniciação à administração de recursos humanos. 4. ed. Barueri, SP: Manole, 2010. 175 p.

COLARES, L. G. T.; FREITAS, C. M. de. Processo de trabalho e saúde de trabalhadores de uma unidade de alimentação e nutrição: entre a prescrição e o real do trabalho. Cadernos de Saúde Pública, v. 23, p. 3011-3020, 2007.

ENZ, C. A. Issues of concern for restaurant owners and managers. Cornell Hotel and Restaurant Administration Quarterly, v. 45, n. 4, p. 315-332, 2004.

FONSECA, K. Z.; SANTANA, G. R. Guia prático para gerenciamento de unidades de alimentação e nutrição. Cruz das Almas, BA: Editora UFRB, 2012. 88p.

FONSECA, P. S. Utilização da análise ergonômica do trabalho, enquanto uma ferramenta da ergonomia para a melhoria da qualidade do trabalho no setor de alimentação coletiva. IV Workshop de Análise Ergonômica do Trabalho; Viçosa. Minas Gerais: Universidade Federal de Viçosa, p. 1-11, 2009.

GOMES, G.S.; JORGE, M.N. Avaliação do Índice de Resto-Ingestão e sobras em uma Unidade Produtora de Refeição Comercial em Ipatinga-MG. Nutrir Gerais, Ipatinga, v. 6, n. 10, p. 857-868, 2012.

JAPUR,C.C;PEREIRA,T.S.;VIEIRA,M.C.M. Ficha Técnica de Preparação. In: VIEIRA M.C.M e JAPUR C.C. (cord.): Gestão da Qualidade em Serviços de Alimentação. Rio de Janeiro: Guanabara Koogan, 2012.p. 217-224.

KILPP, D. S. Controle de estoque de gêneros alimentícios: o caso de uma organização militar de Santa Maria/RS. Trabalho de conclusão de curso (Especialista em Gestão Pública). Rio Grande do Sul: Universidade Federal de Santa Maria, Santa Maria, 2015. 
LIMA, A. P. et al.Avaliação dos aspectos ergonômicos de um restaurante localizado na zona urbana de São Paulo. Revista da Universidade Vale do Rio Verde, v. 15, n. 2, p. 296-305, 2017.

LINS, A.C.A.; MACIEL, M.I.S. Elaboração de fichas técnicas de preparações do buffet do restaurante de um hotel. In: CONGRESSO DE EXTENSÃO, 7, 2007, Recife, PE. Anais...Recife, 2007.

MELO, E. S. de; MACEDO, D. L.; CALAZANS, S. Gestão de custos em serviços de alimentação coletiva: uma revisão sistemática. Revista UNI-RN, v. 16, n. 1/2, p. 110, 2018.

MELO, V. F. Aplicação do sistema de gestão de segurança de alimentos em uma indústria de bebidas orgânicas. 2007. 74 f. Dissertação (Mestrado em Ciências e Tecnologia de Alimentos) Universidade Federal Rural do Rio de Janeiro, UFRRJ, Rio de Janeiro, 2007.

MONTENEGRO, S. S. Os grupos estratégicos no setor de restaurantes self-service de Brasília/ DF. Dissertação (Mestrado em Engenharia de Produção). Faculdade de Engenharia da Universidade Federal de Santa Catarina, Florianópolis, 2003.

NOVELLETO, D. L. L.; PROENÇA, R. P. C. O planejamento do cardápio pode interferir nas condições de trabalho em uma unidade de alimentação e nutrição. Nutrição em Pauta, v. 65, p. 36-40, 2004.

PEREIRA, J. dos S.; VIEIRA, R. B.; FONSECA, K. Z. Características administrativas dos restaurantes self service de Santo Antônio de Jesus-Bahia. Revista Saúde e Desenvolvimento, v. 8, n. 4, p. 36-51, 2016.

PROENÇA, R. P. C. Ergonomia e organização do trabalho em projetos industriais: uma proposta no setor de Alimentação Coletiva. 1993. Dissertação (Mestrado). UFSC, Florianópolis, 1993.

PROENÇA, R. P. da C. Novas tecnologias para a produção de refeições coletivas: recomendações de introdução para a realidade brasileira. Revista de Nutrição, v. 12, n. 1, p. 43-53, 1999.

REBELATO, M. G. Uma análise sobre a estratégia competitiva e operacional dos restaurantes self-service. Revista Gestão \& Produção, v. 4, n. 3, p. 321-334, dez. 1997.

SANT’ANA, H. M. P. Planejamento Físico-Funcional de Unidades de Alimentação e Nutrição. Rio de Janeiro: Editora Rubio, 2012. 
SANTANA, A. M. C. A produtividade em unidade de alimentação e nutrição: aplicabilidade a um sistema de medida e melhoria da produtividade integrando a ergonomia. Tese (Doutorado em Engenharia de Produção). UFSC, Florianópolis, 2002. 270 p.

SANDOVAL, L. C. N.; SPINELLI, M. G. N. Condições ergonômicas de unidades de alimentação e nutrição escolares sob mesma gestão. Nutrivisa, v. 3, n. 3, nov-fev/2017

SEBRAE-SP. Jornal de Negócios. Ano XVIII, n²23. São Paulo: Novembro/2012. Disponível em https://bit.ly/3eTTTvi. Acesso em: 09 jul. 2018.

SOUZA, L. H. L. A manipulação inadequada dos alimentos: Fator de contaminação. Higiene Alimentar, v. 20, n. 146, p. 211-220, 2006.

TEIXEIRA, S.; OLIVEIRA, Z.M.C.; REGO, J.C.; BISCONTINI, T.M.B. (2006) Administração aplicada às unidades de alimentação e nutrição. Rio de Janeiro: Atheneu, 219 p.

VAZ, C. S. Alimentação de coletividade: uma abordagem gerencial. Brasília, 2002.208p.

WHO. World Health Organization. Food borne disease: a focus for health education. 695 Genebra: World Health Organization. 2000; 198p. 
